\title{
The effect of an educational program on quality of life in patients undergoing hemodialysis in western Saudi Arabia
}

\author{
Marwan A. Bakarman, MBBS, FFCM, Maimona K. Felimban, MBBS, Mohammad M. Atta, MD, Nadeem S. Butt, PhD, MS.
}

\section{ABSTRACT

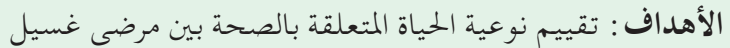

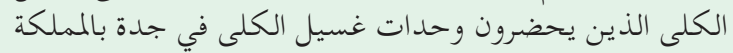

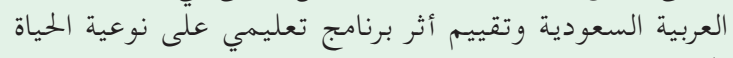 المتعلقة بالصحة.

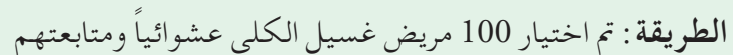

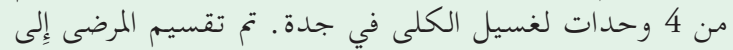

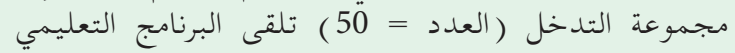

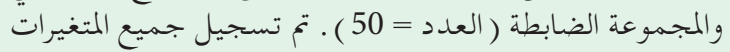

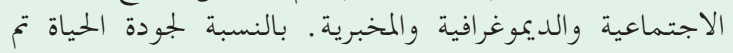

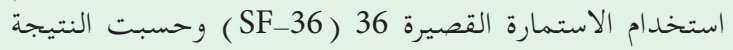

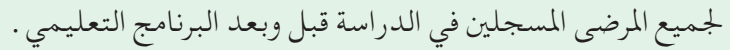

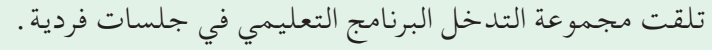 النتائج: كان هناك فرق إِحصائي كبير في الانحراف المعياري

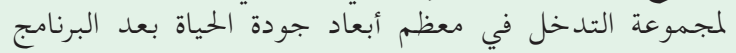

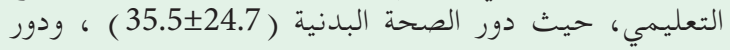

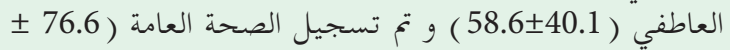

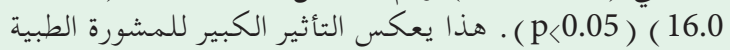

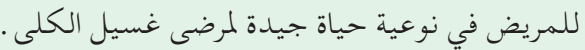

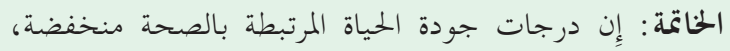

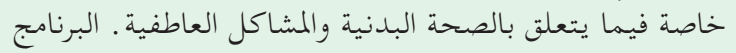

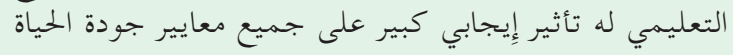 ذات الصلة بالصحة.}

Objectives: To assess health-related quality of life (QOL) among hemodialysis (HD) patients attending HD units in Jeddah, Saudi Arabia and to evaluate the effect of an educational program on health-related QOL.

Method: One hundred HD patients were recruited and followed from 4 different dialysis units in Jeddah, Saudi Arabia between January 2018 and May 2018. The patients were divided into an intervention group $(\mathrm{n}=50)$ receiving educational program and control group $(n=50)$. All sociodemographic and laboratory variables were recorded. The QOL short form 36 (SF-36) questionnaire has been used and the score calculated to all patients enrolled in the study before and after educational program. The participants received the educational program in individualized sessions.

Results: The mean \pm standard deviation in the intervention group were significantly greater than in controls after the educational program in most dimensions of QOL, including role-physical $(35.5 \pm 24.7$ versus $24.5 \pm 23.9, p<0.02)$, roleemotional $(58.6 \pm 40.1$ versus $44.6+43.4, p<0.001)$ and general health $(76.6 \pm 16$ versus $62.9 \pm 19.4$, $p<0.001)$. This reflects high impact of patient counseling in the QOL of HD patients.

Conclusion: The scores of health-related quality of life for HD patients were low. The educational program had significant positive impact on all health-related quality of life parameters.

Saudi Med J 2019; Vol. 40 (1): 66-71 doi: 10.15537/smj.2019.1.23401

From the Department of Family and Community Medicine (Bakarman, Butt), Department of Medicine (Atta), King Abdulaziz University, and Department of Public Health Administration (Felimban), Ministry of Health, Jeddah, Kingdom of Saudi Arabia.

Received 17th July 2018. Accepted 5th of December 2018.

Address correspondence and reprint request to: $D r$. Marwan $A$. Bakarman, Family and Community Medicine Department, Rabigh Faculty of Medicine, King Abdulaziz University, Jeddah, Kingdom of Saudi Arabia.E-mail:mbakarman@kau.edu.sa

ORCID ID: http://orcid.org/ 0000-0002-3515-9850

$\mathrm{E}$ nd stage renal disease (ESRD) is considered as a permanent deterioration in renal function. It is considered a deadly and life-threatening illness, in which the survival can only be sustained by hemodialysis (HD) or peritoneal dialysis. ${ }^{1}$ Therefore, the therapy options are limited to either dialysis or renal transplant. End stage 
renal disease is a lifelong illness that requires continuity of care that includes renal replacement therapy, education, and restriction of food and fluid intake. It is a dreadful sequel of chronic renal failure. Therefore, it has a tremendous impact on the affected patients regarding QOL, morbidity, and mortality. ${ }^{2}$ Published statistics from the United States National Center for Kidney Disease estimates approximately $15 \%$ of the population suffers from chronic renal failure. ${ }^{3}$ These data show that $65 \%$ of the 600,000 suffering from this disease are on HD. A number which is increasing at an alarming percent of approximately $8-10 \%$ annually. According to the most recent annual report, the prevalence of renal failure patients in the Kingdom of Saudi Arabia is 540 per million population. ${ }^{4}$ That number corresponds to 16,315 cases on HD, according to the annual 2016 report of the Saudi Center for Organ Transplantation. ${ }^{4}$

Renal failure has a great impact on patients' health. Data from the literature suggests that the health status among patients suffering from ESRD is very low when compared to the health status of the normal population. This is the reason why health related quality of life (HRQOL) has gained such high attention. ${ }^{5,6}$ In patients with renal failure, some health interventions aim to improve the QOL more than treating the underlying pathology and complications. Therefore, the subjectivity of HRQOL evaluation is noted. ${ }^{5}$

As $\mathrm{HD}$ is a long-term process, patients affected with renal failure need to make various alterations in how they live their life in order to be able to cope with their illness and manage its complications. ${ }^{7}$ For this reason, QOL is more than just the overall health status of a patient. As health is only one of the elements that may affect the overall QOL, there are other important factors that must be considered. These include a patient's family and social status, medical and financial, as well as emotional well-being. ${ }^{8}$ Therefore, renal replacement therapy by itself cannot adequately achieve all the required results unless there is adequate participation of the affected patients themselves in carrying out the different activities that relate to their own self-care. ${ }^{9}$

The improvement in QOL is regarded as a main target in the management of patients with ESRD. ${ }^{10}$ The use of economical and effective treatments is of importance due to the alarming rise in the incidence of

Disclosure. This study was funded by the Deanship of Scientific Research, King Abdulaziz University, Jeddah, Kingdom of Saudi Arabia. (Grant no. 320-828-1439) renal failure, high therapy costs, and overall decline in QOL among patients suffering from renal failure. Given that QOL is regarded as a primary aim in renal failure management, approaching the QOL of life of patients through an educational program is fundamental. The active involvement of patients in their technique of treatment and management is an essential component to the overall improvement of their QOL, as it plays a major role in raising a patient's awareness of their disease. In spite of the much research dealing with the QOL of dialysis patients, in Saudi Arabia such studies are still few. Our educational program is designed to aid in increasing the awareness of patients to their health issues as well as to minimize the unfavorable effects on their overall QOL. Hence, these patients need relevant and proper education for them to be able to cope with their challenges, ${ }^{11,12}$ utilizing care models that are specially tailored to suite Saudi Arabia's social context.

The objectives of this study are to assess healthrelated QOL among HD patients attending HD units in Jeddah, Saudi Arabia and to evaluate the effect of an educational program on HRQOL.

Methods. The study was carried out in Jeddah, Saudi Arabia at 4 different governmental hospital dialysis units, after taking the ethical approval from the Unite of Biomedical Ethics Research Committee, Faculty of Medicine, King Abdulaziz University, Jeddah, Saudi Arabia. The study included all patients undergoing HD between January 2018 and May 2018.

Inclusion criteria include all adult patients on HD, over 18 years of age with regular HD for a duration of at least 6 months, 4 hours per session, 3 times each week. Also, patients who are clinically in a stable condition and are using an arteriovenous fistula for HD access. Exclusion criteria included patients hospitalized for acute illness or have human immunodeficiency virus, patients with active malignancy receiving treatment or mental disability that might make their survey responses uncertain, and patient who would refuse to cooperate.

A randomized interventional study design was used in a group sample sizes of 50 and 50 achieve $84 \%$ power to detect the mean QOL difference of -8.0 between control and intervention groups with estimated group standard deviations of 15.0 and 15.0, and with a significance level (alpha) of 0.05 using a one-sided and two-sample t-test.

One hundred HD patients were recruited and randomly assigned to control $(\mathrm{n}=50)$ and intervention $(n=50)$ groups from 4 hospitals and all of them completed the study and follow-up, with no dropout. The HRQOL was measured by a validated survey for 
SF-36 among the studied HD patients and converted into percentage scores, where higher scores indicate better QOL. This survey obtained data on the QOL of the participating patients. It is composed of 36 questions in the 8 different domains of health. Each patient receive a score from 0 to 100 , where 0 was considered the lowest and 100 is the highest in regard to HRQOL. The patients were interviewed during their outpatient HD sessions and during their regular follow up clinical visits to the dialysis units. All sociodemographic and laboratory variables were recorded. The laboratory investigations included serum blood urea level before and after HD, creatinine, albumin, and hemoglobin which were all measured as baseline and at the end of intervention.

Health education sessions were conducted where the participants received the training in individualized sessionsl. The educational instructions were delivered by the researchers twice a week for a total duration of 8 weeks, and each session lasted for approximately 30 minutes. The educational program was started with an introduction to chronic renal disease, explaining HD, how it works, and why it is important to receive and to comply to HD. The advice on diet was given on an individual basis to the participants in cooperation with a dietician in a verbal and written format highlighting the right amount of calories, protein quantity, serving sizes, including adequate amount of sodium, potassium, and phosphorus. For simplicity, a chart was designed to simplify and illustrate the acceptable quantity of consumed fruit, vegetable, and protein as well as the amount of salt and sugar in junk foods and their effects. The dietary advice given to the participants was based on the National Kidney Foundation Guidelines. Instructions were given to the participants to help them better achieve and comply with issues regarding fluid restriction. Day to day care of the vascular access, simplified drawing and charts, warning signs, as well as hygiene related to the access site were distributed to all patients in the intervention group. Based on fact that different studies have shown the positive effect of emotion-oriented coping strategies, ${ }^{13}$ these issues were discussed with patients on an individual basis. Pre and post assessment of the educational program were carried out by the QOL questionnaire (SF36) given to each patient at the pretest and after finishing the educational program (8 weeks).

Data were entered and analyzed on a personal computer using Statistical Package for Social Sciences (Version 23.0, IBM Corp, Armonk, NY, USA) program. Means and SDs were presented for quantitative variables, frequencies and percentages were given for categorical variables. Independent sample t-test was used to compare significant differences in QOL for control and intervention groups. Kolmogrov Smirnov test is used to evaluate the assumption of normality.

Results. One hundred HD patients were recruited and followed from the 4 hospitals and all of them completed the study and follow-up and there were no dropouts. We divided the patients into an intervention group $(n=50)$ and control group $(n=50)$. The mean age was $43.2 \pm 12.1$ years, $56 \%$ patients were female. Thirtythree percent were single and more than half (54\%) were married. Regarding educational, $38 \%$ of them had high a school degree, and 26\% were college graduates. Most of the participants were unemployed (76\%), the majority (98\%) received 3 dialysis sessions per week. Hypertension was the main cause of chronic kidney disease (CKD) (59\%). Both groups, intervention and control, are similar in sociodemographic characteristics $(p>0.05)$.

The mean scores of QOL in HD patients before the educational program in the intervention and control groups are shown in Table 1. Using independent sample t-test, no significant difference was observed between the 2 groups in all dimensions of HRQOL questionnaire before the education program. To compare the difference between intervention and control group (post-test), after the health education program. Paired t test was used and the results are presented in Table 2.

Table 1 - Comparison of SF-36 subscale between the intervention and the control groups before education program.

\begin{tabular}{|c|c|c|c|}
\hline Quality of life aspect & Group & Mean \pm SD & $P$-value* \\
\hline \multirow{2}{*}{ Physical functioning } & Intervention & $56.9 \pm 22.2$ & \multirow{2}{*}{0.31} \\
\hline & Control & $51.3 \pm 23.5$ & \\
\hline \multirow{2}{*}{ Role-physical } & Intervention & $23.0 \pm 28.0$ & \multirow{2}{*}{0.64} \\
\hline & Control & $25.0 \pm 27.1$ & \\
\hline \multirow{2}{*}{ Role-emotional } & Intervention & $34.6 \pm 41.4$ & \multirow{2}{*}{0.11} \\
\hline & Control & $47.3 \pm 43.1$ & \\
\hline \multirow{2}{*}{ Energy and fatigue } & Intervention & $52.1 \pm 13.7$ & \multirow{2}{*}{0.196} \\
\hline & Control & $56.6 \pm 16.9$ & \\
\hline \multirow{2}{*}{ Emotional well being } & Intervention & $59.1 \pm 13.4$ & \multirow{2}{*}{0.82} \\
\hline & Control & $60.3 \pm 17.3$ & \\
\hline \multirow{2}{*}{ Social functioning } & Intervention & $55.5 \pm 19.7$ & \multirow{2}{*}{0.81} \\
\hline & Control & $57.2 \pm 25.0$ & \\
\hline \multirow{2}{*}{ Pain } & Intervention & $65.4 \pm 17.2$ & \multirow{2}{*}{0.17} \\
\hline & Control & $70.2 \pm 17.5$ & \\
\hline \multirow{2}{*}{ General health } & Intervention & $65.7 \pm 17.1$ & \multirow{2}{*}{0.89} \\
\hline & Control & $65.2 \pm 17.8$ & \\
\hline \multirow{2}{*}{ Total HRQOL } & Intervention & $51.5 \pm 13.2$ & \multirow{2}{*}{0.39} \\
\hline & Control & $54.1 \pm 15.0$ & \\
\hline
\end{tabular}


As Table 3 illustrates, all laboratory tests showed no significant changes between the intervention and control group before the educational program for HD patients, while Table 4 demonstrates statistical significant change only in hemoglobin level after the educational program.

Discussion. End-stage renal disease is a serious consequence of progressive $\mathrm{CKD}$ and results in significant morbidity and mortality globally. Chronic kidney disease is a worldwide health issue and a major health concern. ${ }^{14,15}$ Patients on HD face different problems, which affect many aspects of their life. ${ }^{16}$ Evaluating HRQOL in chronic diseases such as CKD has become a mainstay of medical management and treatment of the patient. Health related QOL is a multidimensional concept that reflects the health of a patient on a physical and mental basis. Therefore, evaluating QOL in HD patients will help to assess the provided care and evaluate the efficacy of medical treatment. ${ }^{17}$ Multiple international studies have shown the negative impact of $\mathrm{CKD}$ on QOL in patients undergoing $\mathrm{HD}$, which ultimately affects their lifestyle. The overall conclusion of these studies demonstrated that QOL among this subset of patients is low. ${ }^{18}$ Compared to the general population, the study participants showed low scores on all subscales of the SF-36. Essentially, this is due to the burden of the symptoms of their illness and also due to the frequency of dialysis sessions. Moreover, compared to other chronic diseases, such as chronic gastritis ${ }^{19}$ or

Table 2 - Comparison of SF-36 subscale between the intervention and the control groups after educational program.

\begin{tabular}{|c|c|c|c|}
\hline Quality of life aspect & Group & Mean \pm SD & $P$-value ${ }^{*}$ \\
\hline \multirow{2}{*}{ Physical functioning } & Intervention & $66.0 \pm 23.3$ & \multirow{2}{*}{$0.00^{\dagger}$} \\
\hline & Control & $48.6 \pm 26.8$ & \\
\hline \multirow{2}{*}{ Role-physical } & Intervention & $35.5 \pm 24.7$ & \multirow{2}{*}{$0.02^{\dagger}$} \\
\hline & Control & $24.5 \pm 23.9$ & \\
\hline \multirow{2}{*}{ Role-emotional } & Intervention & $58.6 \pm 40.1$ & \multirow{2}{*}{$0.00^{\dagger}$} \\
\hline & Control & $44.6+43.4$ & \\
\hline \multirow{2}{*}{ Energy and fatigue } & Intervention & $64.1 \pm 16.2$ & \multirow{2}{*}{$0.00^{\dagger}$} \\
\hline & Control & $55.4 \pm 18.0$ & \\
\hline \multirow{2}{*}{ Emotional well being } & Intervention & $73.6 \pm 12.0$ & \multirow{2}{*}{$0.00^{\dagger}$} \\
\hline & Control & $64.1 \pm 20.5$ & \\
\hline \multirow{2}{*}{ Social functioning } & Intervention & $67.7 \pm 23.9$ & \multirow{2}{*}{$0.00^{\dagger}$} \\
\hline & Control & $49.2 \pm 32.7$ & \\
\hline \multirow{2}{*}{ Pain } & Intervention & $73.2 \pm 19.8$ & \multirow{2}{*}{$0.03^{\dagger}$} \\
\hline & Control & $79.0 \pm 19.4$ & \\
\hline \multirow{2}{*}{ General health } & Intervention & $76.6 \pm 16.0$ & \multirow{2}{*}{$0.00^{\dagger}$} \\
\hline & Control & $62.9 \pm 19.4$ & \\
\hline \multirow{2}{*}{ Total HRQOL } & Intervention & $64.4 \pm 12.2$ & \multirow{2}{*}{$0.00^{\dagger}$} \\
\hline & Control & $53.5 \pm 14.6$ & \\
\hline
\end{tabular}

diabetes mellitus, ${ }^{20}$ participants of the present study reported lower HRQOL in general health $(65 \%)$ and greater defects in physical functioning (54\%). This fact might be due to patients with ESRD requiring dialysis on a near-daily basis, with each session lasting for around 4 to 5 hours and frequently accompanied by unpleasant symptoms. Health related QOL is a multifaceted view which represents how a patient feels his well-being regarding physical, psychological, and social aspects of health. ${ }^{21}$ It is an important indicator for the assessment and evaluation of a HD patient care program..$^{22}$ It also has a significant role in improving the health literacy of HD patients and improves their outcome. The proposed healthcare plan for CKD patients has shifted from only improving the survival to achieving an acceptable QOL. ${ }^{23}$

According to the literature, it is essential to conduct self-care educational programs for helping HD patients increase their QOL. Different education initiatives such as group teaching and counseling may assist in achieving this objective. ${ }^{24}$ Hemodialysis patients have particular dietary requirements and need to take a variety of medications. All these factors mandate continuous education to help HD patients better cope with changes encompassing both physical and

Table 3 - Blood tests of hemodialysis patients in the study and control groups before the intervention program.

\begin{tabular}{lccc}
\hline & Group & Mean \pm SD & $P$-value* \\
\hline Hemoglobin level & Intervention & $10.9+1.1$ & 0.07 \\
& Control & $11.3 \pm 0.9$ & \\
Urea level & Intervention & $10.0 \pm 3.4$ & 0.1 \\
Creatinine level & Control & $11.0 \pm 29$ & \\
& Intervention & $7.3 \pm 3.5$ & 0.08 \\
Albumin level & Control & $6.4 \pm 3.7$ & \\
& Intervention & $36.4 \pm 3.6$ & 0.7 \\
\hline & Control & $36.1 \pm 3.5$ & \\
\hline
\end{tabular}

Table 4 - Blood tests of hemodialysis patients in the study and control groups after intervention program.

\begin{tabular}{lccc}
\hline & Group & Mean \pm SD & $P$-value \\
\hline \multirow{2}{*}{ Hemoglobin level } & Intervention & $11.7 \pm 0.9$ & \multirow{2}{*}{$0.00^{\dagger}$} \\
& Control & $11.1 \pm 1.1$ & \\
Urea level & Intervention & $7.9 \pm 20.4$ & \multirow{2}{*}{0.27} \\
& Control & $8.5 \pm 2.2$ & \\
Creatinine level & Intervention & $7.3 \pm 3.4$ & 0 \\
& Control & $6.4 \pm 3.6$ & \\
Albumin level & Intervention & $36.8 \pm 3.2$ & \multirow{2}{*}{0.10} \\
\hline \multicolumn{2}{c}{${ }^{*}$ Independent t-test, ${ }^{\dagger}$ Significance level at $p<0.05$} \\
\end{tabular}


emotional aspects. ${ }^{9}$ There are numerous educational methods for health promotion; it can be complemented by face to face counseling and video education. ${ }^{25}$ The intervention group received face to face counseling educational program during HD sessions, held twice a week. This method was used in a research by Ghadam et al. ${ }^{9}$ According to the study findings, the impact of our educational program on the QOL improvement of $\mathrm{HD}$ patients was assessed after 8 weeks. The results showed a significant improvement in each domain after counseling. Total QOL score improvement postintervention increased from 51.54 to 64.43 . These finding are quite similar to the study of Ghadam et al. ${ }^{9}$ The role limitation scores were significantly increased due to emotional problems and well-being, energy, fatigue, social function, general health, and all HRQOL aspects $(p<0.05)$. Hence, there is a difference in the mean pre-test and post-test score for all of the domains mentioned. These findings support the fact that the education initiatives in the form of face to face counseling can help in improving the patient's HRQOL in patients suffering from CKD. Similar results were reported by Ghadam et al.2016, ${ }^{9}$ showing QOL increased in all domains in face to face educational groups $(p<0.001)$ in $\mathrm{HD}$ patients following a self-care education program. Bahodri et $\mathrm{al}^{26}$ showed similar results in their study. Educational programs held through counseling patients have a positive effect on HRQOL and could help in providing mental support and understanding of the disease as well as improving the self-esteem of the patients undergoing HD. Our study is comparable with the work acomplish by Thomas et $\mathrm{al}^{27}$ who found that patient counseling had a powerful impact on the QOL in patients receiving $\mathrm{HD}$.

Furthermore, training of $\mathrm{HD}$ patients regarding health promotion had a positive impact on their QOL and reduced dependency in daily living and achieving autonomous function. Such programs help motivate patients to participate in social activities as well as reduce the economic burden of chronic disease on patients and their families.

Since all patients that participated in our study were enrolled from governmental hospitals only, the main limitation was the relatively small sample size. This fact may restrict the study ability to generalize the results. Due to this, further studies with a larger sample from different governmental, non-governmental hospitals and longer follow-up are recommended. In addition, future studies utilizing different education methods, especially those addressing physical health, social, and emotional issues are suggested.
In conclusion, HD patients show a substantial reduction in HRQOL in all health domains. It is a major challenge for healthcare providers to develop various strategies to help improve the HRQOL as part of a well-designed HD care program. Empowerment of education programs and counseling of HD patients leads to a clinically and statistically significant improvement. These programs will improve social function, emotional, physical function, general health, total HRQOL score, and hemoglobin level. The overall QOL score was improved in the patients who received the intervention and became worse in the control group. The educational program had a significant positive impact on all health-related QOL parameters. Our results highlight the importance of providing periodic counseling at regular intervals to improve the QOL of HD patients.

Acknowledgment. The authors would like to acknowledge and thank Deanship of Scientific Research (DSR), King Abdulaziz University, Jeddah, Saudi Arabia for technical and financial support. We would also like to thank Ms. Bridget A. Somers for English language editing.

\section{References}

1. Landreneau K, Lee K, Landreneau MD. Quality of life in patients undergoing hemodialysis and renal transplantation-a meta-analytic review. Nephrol Nurs J 2010; 37: 37-44.

2. Nemati E, Motalebi M. A better quality of life in hemodialysis patients with viral hepatitis: is it a reality. Hepat Mon 2013; 13: e15525.

3. Centers for Disease Control and Prevention. National Chronic Kidney Disease Fact Sheet. Atlanta (GA): US Department of Health and Human Services, Centers for Disease Control and Prevention; 2017.

4. Saudi Center for Organ Transplantation (SCOT). Annual Report 2016, Hemodialysis in the Kingdom of Saudi Arabia. KSA: Saudi Center for Organ Transplantation; 2016.

5. Klarenbach SW, Tonelli M, Chui B, Manns BJ. Economic evaluation of dialysis therapies. Nat Rev Nephrol 2014; 10: 644-652.

6. Mazairac AH, Grooteman MP, Blankestijn PJ, Penne EL, Lars Penne E, van der Weerd NC, et al. Differences in quality of life of hemodialysis patients between dialysis centers. Qual Life Res 2012; 21: 299-307.

7. Papkour A, Zeidi I, Chatzisarantis N, Molsted S, Harrison A, Plotnikoff RV. Effects of action planning and coping planning within the theory of planned behaviour: a physical activity study of patients undergoing hemodialysis. Psychology of Sport and Exercise 2011; 12: 609-614.

8. Bayoumi M, Al Harbi A, Al Suwaida A, Al Ghonaim M, Al Wakeel J, Mishkiry A. Predictors of quality of life in hemodialysis patients. Saudi Journal of Kidney Diseases Transplantation 2013; 24: 254-259.

9. Ghadam MS, Poorgholami F, Jahromi ZB, Parandavar N, Kalani N, Rahmanian E. Effect of self-care education by faceto-face method on the quality of life in hemodialysis patients (relying on ferrans and powers questionnaire). GlobJ Health Sci 2016; 8: 121-127. 
10. Lii YC, Tsay SL, Wang TJ. Group intervention to improve quality of life in haemodialysis patients. J Clin Nurs 2007; 16: 268-275.

11. Mapes DL, Lopes A, Satayathum S, Mccullough KP, Goodkin DA, Locatelli F, et al. Health-related quality of life as a predictor of mortality and hospitalization: the dialysis outcomes and practice patterns study (DOPPS). Kidney International 2003; 64: 339-349.

12. Yang F1, Griva K, Lau T, Vathsala A, Lee E, Ng HJ, et al. Health-related quality of life of Asian patients with end-stage renal disease (ESRD) in Singapore. Qual Life Res 2015; 24: 2163-2171.

13. Yeh SC, Chou HC. Coping strategies and stressors in patients with hemodialysis. Psychosom Med 2007; 69: 182-90.

14. Hill NR, Fatoba ST, Oke JL, Hirst JA, O'Callaghan CA, Lasserson DS, et al. Global prevalence of chronic kidney disease - a systematic review and meta-analysis. PLoS One 2016; 11: e0158765.

15. Seck S. Issues of renal replacement therapy in elders living low-income African countries. Nephrourol Mon 2012; 4: 648-649.

16. Kagar JM, Javadpour S, Taheri L, Poorgholami F. Effect of nurse-led telephone follow ups (tele-nursing) on depression, anxiety and stress in hemodialysis patients. Global Journal of Health Science 2016; 8: 168-173.

17. Bale C, Douglas A, Jegatheesan D, Pham L, Sonny Huynh S, Mulay A, et al. Psychosocial factors in end-stage kidney disease patients at a tertiary hospital in Australia. International Journal of Nephrology 2016; 2016: 2051586.

18. Wingard R. Patient education and the nursing process: meeting the patient's needs. Nephrol Nurs J 2005; 32: 211-214.
19. Wen Z, Li X, Lu Q, Brunson J, Zhao M, Tan J, et al. Health related quality of life in patients with chronic gastritis and peptic ulcer and factors with impact: a longitudinal study. BMC Gastroenterol 2014; 14: 149.

20. Javanbakht M, Abolhasani F, Mashayekhi A, Baradaran HR, Jahangiri noudeh Y. Health related quality of life in patients with type 2 diabetes mellitus in Iran: a national survey. PLoS One 2012; 7: e44526.

21. Yin S, Njai R, Barker L, Siegel PZ, Liao Y. Summarizing healthrelated quality of life (HRQOL): development and testing of a one-factor model. Popul Health Metr 2016; 14: 22.

22. Tallis K. How to improve the quality of life in patients living with end stage renal failure. Ren Soc Aust J 2005; 1: 18-24.

23. Finkelstein FO, Wuerth D, Finkelstein SH. Health related quality of life and the CKD patient: challenges for the nephrology community. Kidney Int 2009; 76: 946-952.

24. Mohsen MM, Mohammed WY, Riad NA, Atia GA. Impact of designed nursing intervention protocol for hemodialysis patients on patient's outcomes. Journal of Biology, Agriculture and Healthcare 2013; 3: 53-67.

25. Karimi-Moonaghi H, Hasanzadeh F, Shamsoddini S, Emamimoghadam Z, Ebrahimzadeh S. A comparison of face to face and video-based education on attitude related to diet and fluids: Adherence in hemodialysis patients. Iran J Nurs Midwifery Res 2012; 17: 360-364.

26. Bahadori M, Ghavidel F, Mohammadzadeh S, Ravangard R. The effects of an interventional program based on self-care model on health-related quality of life outcomes in hemodialysis patients. J Educ Health Promot 2014; 3: 110.

27. Thomas D, Joseph J, Francis B, Mohanta GP. Effect of patient counseling on quality of life of hemodialysis patients in India. Pharm Pract (Granada) 2009; 7: 181-184. 